\title{
Influence of the synthesis conditions on the pore structure and stability of MCM-41 materials containing aluminium or titanium
}

\author{
M.M.L. Ribeiro Carrott, C. Galacho, F.L. Conceição and P.J.M. Carrott \\ Centro de Química de Évora and Departamento de Química, Universidade de Évora, Colégio \\ Luís António Verney, 7000-671 Évora, Portugal
}

A comparison of the pore structural properties of MCM-41 containing titanium, prepared at room temperature, with those of aluminosilicate grades is presented. The influence on the structural characteristics of using different metal sources and metal content is also considered. Additionally, the stability of Al-MCM-41 and Ti-MCM-41 samples, with Si/M=30, towards prolonged exposure to pure water vapour at $298 \mathrm{~K}$ was investigated.

\section{INTRODUCTION}

Amongst the most important features of ordered mesoporous materials for their use in catalysis are the extremely high surface area, which potentially allows an efficient dispersion of active sites, and the large pore diameters that favour the diffusion of bulky molecules. However, the introduction of the heteroatoms into ordered mesoporous silicas to make them catalytically active can lead to a decrease in the quality of the pore structure as compared with the pure silica grades, the extent of which may depend on the preparation conditions. Therefore, the control of the quality of the pore structure is a relevant aspect to consider.

MCM-41 containing aluminium or titanium have been commonly used, respectively, for acid or oxidation catalysed reactions, and they are frequently obtained by grafting of active species onto the inner surface of the mesopores of a pure silica material or by its incorporation in the walls during synthesis [1]. This is usually done by a hydrothermal route, but an alternative procedure at room temperature was reported for Al-MCM-41, that allows the preparation in reduced times of well structured materials containing aluminium mainly tetracoordinated [2]. Furthermore, we have shown [3] that samples prepared by this method, even with very low $\mathrm{Al}$ content $(\mathrm{Si} / \mathrm{Al} \geq 138)$, had enough acidity to catalise the reaction of double bond position of 1-butene, without the need of post-synthesis cationic exchange treatments, usually required in hydrothermal synthesis to obtain the protonated forms, that cause further disruption of the pore structure. Also, we have adapted the room temperature method to obtain Ti-MCM-41 which showed negligible acidity, as compared with a Ti grafted MCM sample, which is an advantage for selectivity and activity of some redox reactions [4].

In the present study we have used other metal sources and higher metal contents and present a comparison of the effects of introduction of aluminium and titanium on the pore structural properties. Additionally, considering that a severe limitation of ordered mesoporous materials, either pure silica grades [5] as well as some hydrothermally synthesised MCM-41 containing aluminium [6] or titanium [7], is that structural changes usually occur in the presence of water vapour, a study of the stability towards water vapour at $298 \mathrm{~K}$ is also presented. 


\section{EXPERIMENTAL}

Pure silica MCM-41 samples were prepared at room temperature following a procedure previously reported [8], but with the tetraethoxysilane (TEOS) being dissolved in an equal volume of propan-2-ol (Si-p) or ethanol (Si-e) prior to the addition to the surfactant and ammonia mixture. The preparation in the presence of the alcohols had the purpose to use conditions similar to those used in metal containing samples. The titanosilicate MCM-41 samples were prepared by a similar method to that previously developed for aluminosilicate samples [2], but using always the same volume (equal to that of TEOS) of the solution in propan-2-ol of the titanium alcoxides, whose quantities were varied to achieve the required molar ratio. Titanium ethoxide, isopropoxide and n-butoxide were used as metal sources, respectively, for samples Ti-Ep-X, Ti-Pp-X, and Ti-Bp-X (with $\mathrm{X}=$ nominal $\mathrm{Si} / \mathrm{Ti}$ ). The samples containing aluminium, designated $\mathrm{Al}-\mathrm{Pp}-\mathrm{X}$ (with $\mathrm{X}=$ nominal $\mathrm{Si} / \mathrm{Al}$ ) were prepared according to the room temperature method in ref.[2] using aluminium isopropoxide in propan2-ol. Sample Al-Be-30 was prepared in a similar way but using aluminium tert-butoxide dissolved in ethanol, as it is more soluble in this alcohol. In the synthesis of Al-P-30 and Al-B-30, the alcoxide was directly dissolved in the TEOS.

In all syntheses, hexadecyltrimethylammonium bromide was used as template and the alcohol and water were previously bi-distilled. In all cases, after stirring for $1 \mathrm{~h}$, the products were recovered by filtration and washed with bi-distilled water, dried at 343K and finally calcined in air at $823 \mathrm{~K}$ (heating rate of $3 \mathrm{Kmin}^{-1}$ ) for a minimum of $11 \mathrm{~h}$.

All samples were characterised by X-ray diffraction and nitrogen adsorption at $77 \mathrm{~K}$. The XRD measurements were obtained on a Bruker AXS, D8 Advance, powder diffractometer using $\mathrm{CuK}_{\alpha}$ radiation. Nitrogen adsorption isotherms at $77 \mathrm{~K}$ were determined on a $\mathrm{CE}$ Instruments Sorptomatic 1990. Diffuse reflectance UV-Vis spectra of the titanium containing samples were collected on a Varian Cary 5-E. The stability towards water was evaluated by measuring two consecutive water vapour adsorption-desorption isotherms at 298K, followed by XRD and nitrogen adsorption characterization. Isotherms of n-pentane and n-hexane, respectively, for Ti-Ep-30 and Al-Pp-30, were also determined before and after the exposure to water vapour. Water and hydrocarbon vapour adsorption isotherms at $298 \mathrm{~K}$ were determined in a vacuum gravimetric apparatus using a CI Electronics MK2 vacuum microbalance with a Robal control unit and Edwards Barocel 600 capacitance manometers.

\section{RESULTS AND DISCUSSION}

\subsection{Effect of metal introduction on the pore structural characteristics of MCM-41}

It can be seen in Figs 1-4 that either pure silica sample prepared in the presence of propan-2-ol or metal containing samples, present X-ray diffraction patterns and nitrogen adsorption isotherms typical of MCM-41 materials. Practically coincident results to those of Si-P were obtained for pure silica samples prepared in the absence of alcohol and in the presence of ethanol.

In all cases, the three or four peaks observed at low diffraction angles could be indexed to only one hexagonal phase and the unit cell parameter values are presented in Table 1. Additionally, no peaks at higher angles were observed, indicating the absence of any crystalline phases containing aluminium or titanium, even for the higher metal contents used.

In most cases the nitrogen isotherms were completely reversible, except for the samples for which the desorption points are shown, and which presented hysteresis at high relative 
pressures after the pore filling step, indicating interparticle agglomeration. The total and external surface areas and the pore volume were estimated in the usual manner from the corresponding $\alpha_{\mathrm{s}}$ plots, constructed using standard data for adsorption of nitrogen on nonporous partially hydroxylated silica, and the results are presented in Table 1. Although it is well know that the surface area is overestimated and that the hydraulic pore width approach underestimates the pore size $[9,10]$ the values will be considered for comparative analysis between samples. It is evident from the results presented that all samples have considerably high pore volumes and surface areas, but that the exact pore structural parameters as well as the regularity and uniformity of the pore structure depend on some synthesis parameters.

In general, the introduction of titanium in the MCM-41 materials has some similar effects to those of aluminium, in the sense that some loss of pore structure quality is observed and this increases with increasing the metal content, which qualitatively agrees with the previous findings for Al-MCM-41 [2]. However, it is quite clear from the comparison done in Figs. 1 and 2 that the introduction of titanium has a less disruptive effect on the pore structure than aluminium, the difference between the two metals being more pronounced with increasing metal content. In fact, it can be seen that in particular for the nominal molar ratios of 30 and 10, the Ti-MCM-41 samples present steeper pore filling steps and better defined XRD peaks than those of Al-MCM-41 with comparable or even lower $(\mathrm{Si} / \mathrm{Al}=15)$ aluminium content. Additionally, the nitrogen adsorption isotherm of the Al-Pp-15 sample presents pronounced hysteresis at high pressures, associated with secondary mesoporosity, in contrast with that of Ti-Pp-10, which is almost completely reversible.

Therefore, the results show that the previously proposed method to obtain Al-MCM-41 at room temperature can also be used with even better results for the preparation of Ti-MCM-41 materials. This synthesis can also be carried out with other titanium alcoxides giving samples with very similar pore volumes and pore uniformity as can be seen in Fig. 3(a) and Table 1, for the series prepared with $\mathrm{Si} / \mathrm{Ti}=50$. However, it can be seen that with titanium n-butoxide the regularity appears to be smaller, which can be due, at least partially, to the n-butanol formed by the hydrolysis and its higher tendency to solubilize in the micelles than the smaller chain alcohols. Although the expected amount of n-butanol formed is less than the one reported to give another coexisting hexagonal and a lamellar phase [11], it may be sufficient to cause some disordering of the hexagonal array of the micelles.

Additionally, we noticed that these three titanium alcoxides gave completely clear solutions in both alcohols, while the aluminium isopropoxide was not completely soluble and the original solution in freshly bi-distilled propan-2-ol probably contained already some polymerised species. The attempt to use other aluminium source and dissolution directly in TEOS, gave materials with very similar pore volumes and total surface areas as can be seen in Fig. 4(a) and Table 1. Small differences are observed with regard to external surface area, lower values being obtained when aluminium tert-butoxide is used as metal source. It is evident from the XRD patterns that the direct dissolution in the TEOS results in materials with slightly lower degree of structural ordering, although no significant differences are observed with regard to pore volume and uniformity.

So, it can be noted that, either with $\mathrm{Ti}$ or $\mathrm{Al}$, the pore structural characteristics are not affected very much by the metal source used in this study, but the changes are more pronounced with increasing metal content. This can result either from the successful incorporation of the bigger metal species or from the presence of extra-structural polymerised species, which can be formed in the synthesis gel and also during the calcination step. In fact, in the original work [2] the authors reported that, although the aluminium is predominantly 

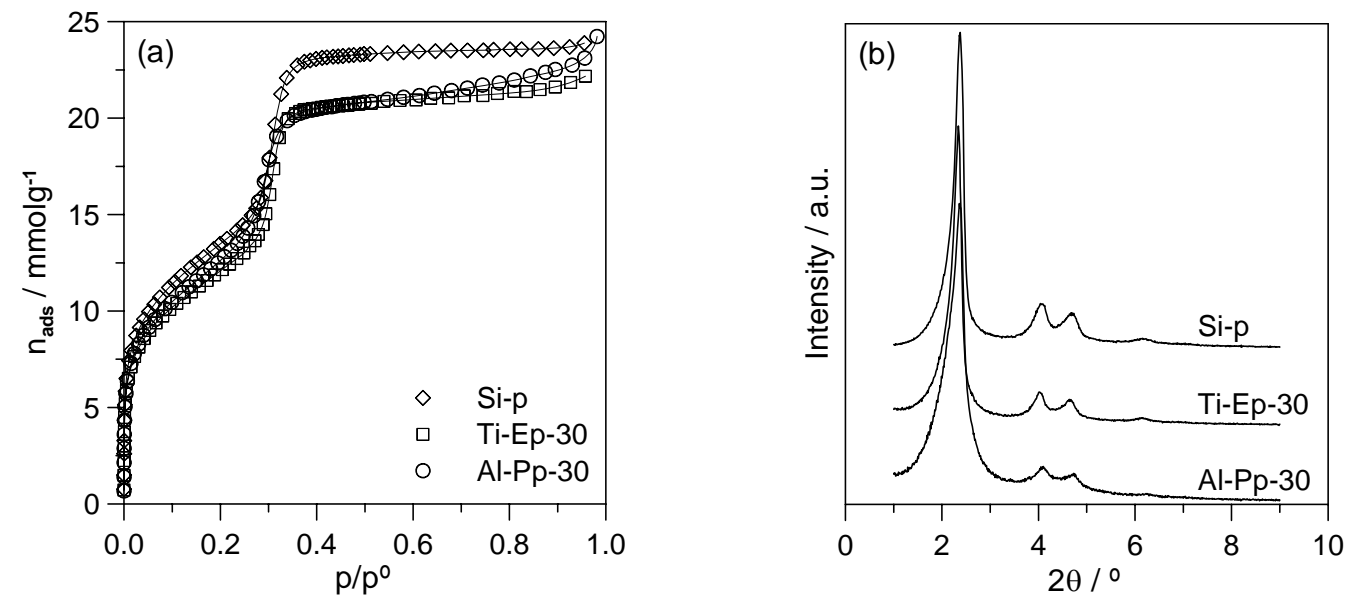

Fig. 1. (a) Nitrogen adsorption isotherms, at $77 \mathrm{~K}$, and (b) X-ray diffraction patterns of pure silica MCM-41 prepared in the presence of propan-2-ol and Ti- and Al-MCM-41 of Si/M=30.
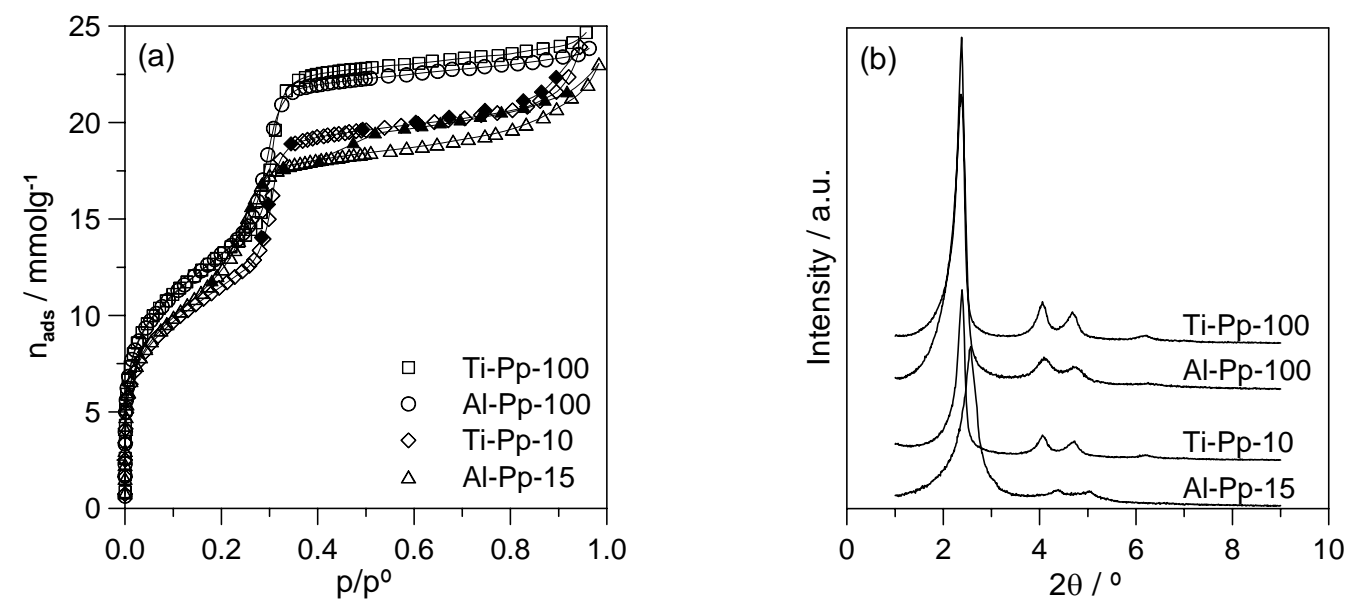

Fig. 2. (a) Nitrogen adsorption-desorption isotherms, at 77K, and (b) X-ray diffraction patterns of Ti-MCM-41 (Si/Ti=100 and 10 ) and Al-MCM-41 (Si/Ti=100 and 15). (empty symbols: adsorption, filled symbols: desorption)
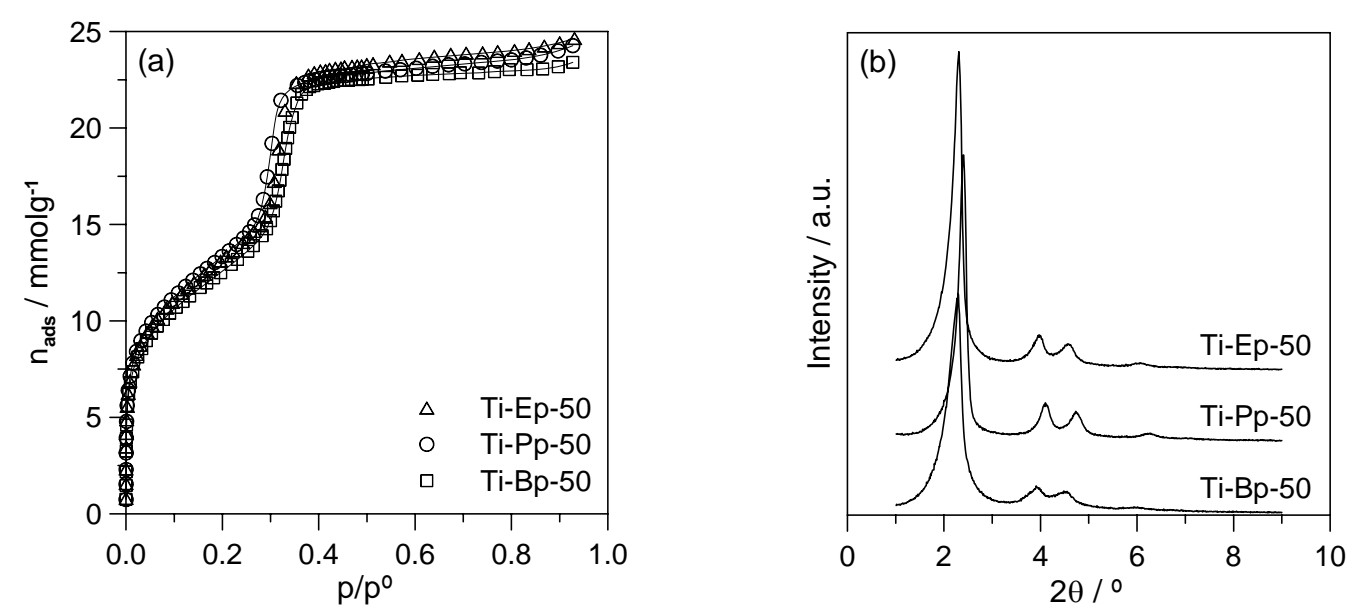

Fig. 3. (a) Nitrogen adsorption isotherms, at $77 \mathrm{~K}$, and (b) X-ray diffraction patterns of Ti-MCM-41 of $\mathrm{Si} / \mathrm{Ti}=50$ prepared with different titanium alcoxides. 

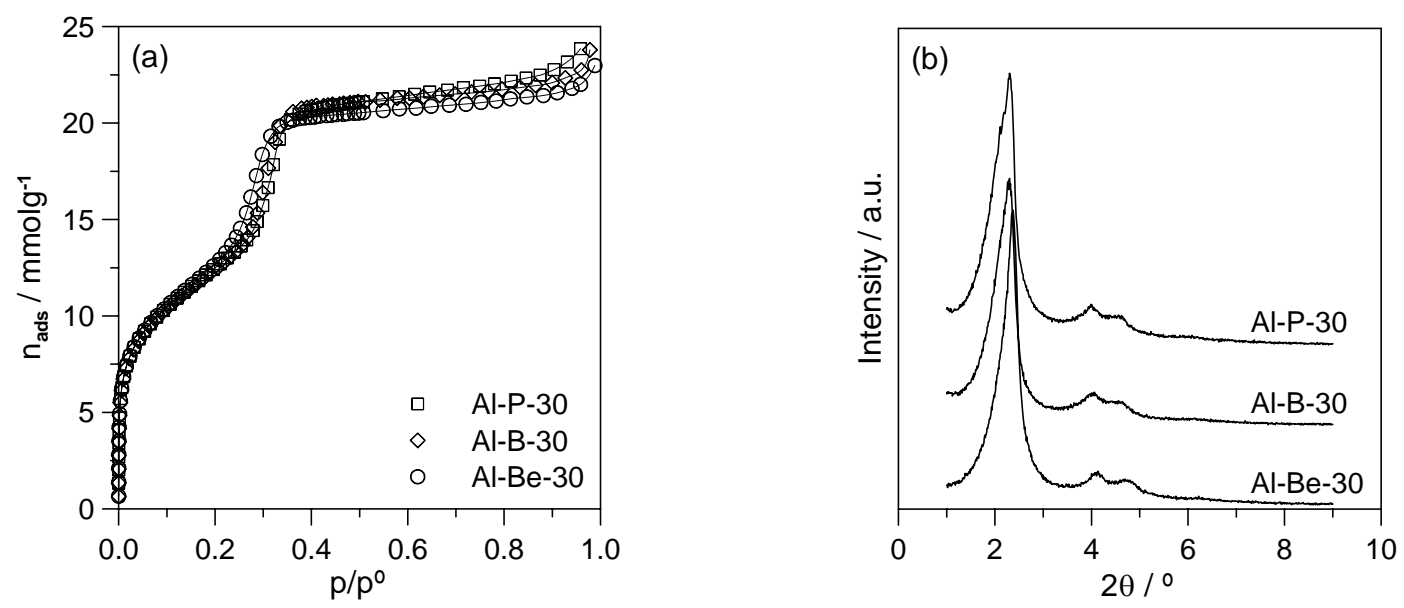

Fig. 4. (a) Nitrogen adsorption isotherms, at $77 \mathrm{~K}$, and (b) X-ray diffraction patterns of $\mathrm{Al}-\mathrm{MCM}-41$ of $\mathrm{Si} / \mathrm{Al}=30$ prepared with different aluminium alcoxides and conditions.

Table 1

Results of the structural characterisation by XRD and nitrogen adsorption at 77K.

\begin{tabular}{|c|c|c|c|c|c|c|c|}
\hline \multirow{2}{*}{ Sample } & \multirow{2}{*}{$\begin{array}{c}\text { Metal } \\
\text { Source* }^{*}\end{array}$} & \multirow{2}{*}{ Alcohol } & \multirow{2}{*}{$\begin{array}{c}\text { XRD } \\
\begin{array}{c}a_{0} \\
(\mathrm{~nm})\end{array}\end{array}$} & \multicolumn{4}{|c|}{ Nitrogen adsorption at $77 \mathrm{~K}^{\#}$} \\
\hline & & & & $\begin{array}{c}\mathrm{A}_{\mathrm{s}} \\
\left(\mathrm{m}^{2} \mathrm{~g}^{-1}\right)\end{array}$ & $\begin{array}{c}A_{\text {ext }} \\
\left(m^{2} g^{-1}\right)\end{array}$ & $\begin{array}{c}V_{\mathrm{p}} \\
\left(\mathrm{cm}^{3}(\mathrm{liq}) \mathrm{g}^{-1}\right)\end{array}$ & $\begin{array}{l}\mathrm{d}_{\mathrm{p}}(\mathrm{H}) \\
(\mathrm{nm}) \\
\end{array}$ \\
\hline Si-p & - & propan-2-ol & 4.34 & 1063 & 17 & 0.80 & 3.06 \\
\hline Si-e & - & ethanol & 4.33 & 1057 & 17 & 0.79 & 3.04 \\
\hline Ti-Pp-100 & TIP & propan-2-ol & 4.34 & 1042 & 32 & 0.79 & 3.13 \\
\hline Ti-Ep-50 & $\mathrm{TE}$ & propan-2-ol & 4.45 & 1033 & 33 & 0.80 & 3.20 \\
\hline Ti-Pp-50 & TIP & propan-2-ol & 4.29 & 1053 & 33 & 0.79 & 3.10 \\
\hline Ti-Bp-50 & TB & propan-2-ol & 4.51 & 995 & 23 & 0.78 & 3.21 \\
\hline Ti-Ep-30 & $\mathrm{TE}$ & propan-2-ol & 4.36 & 955 & 28 & 0.72 & 3.11 \\
\hline Ti-Pp-10 & TIP & propan-2-ol & 4.33 & 902 & 103 & 0.63 & 3.15 \\
\hline Al-Pp-100 & AIP & propan-2-ol & 4.31 & 1032 & 32 & 0.77 & 3.08 \\
\hline Al-Pp-30 & AIP & propan-2-ol & 4.32 & 976 & 71 & 0.70 & 3.09 \\
\hline Al-Be-30 & ATB & ethanol & 4.32 & 980 & 52 & 0.69 & 2.97 \\
\hline Al-P-30 & AIP & - & 4.42 & 975 & 78 & 0.70 & 3.12 \\
\hline Al-B-30 & ATB & - & 4.41 & 971 & 49 & 0.71 & 3.08 \\
\hline Al-Pp-15 & AIP & propan-2-ol & 4.04 & 920 & 108 & 0.59 & 2.91 \\
\hline
\end{tabular}

*TE,TIP and TB - titanium ethoxide, isopropoxide and n-butoxide, respectively; AIP and ATB aluminium isopropoxide and tert-butoxide, respectively.

${ }^{\#}$ Considering $\sigma_{\mathrm{N} 2}=0.162 \mathrm{~nm}^{2}$ and $\rho_{\mathrm{N} 2}=0.808 \mathrm{~g} \mathrm{~cm}^{-3}$. 


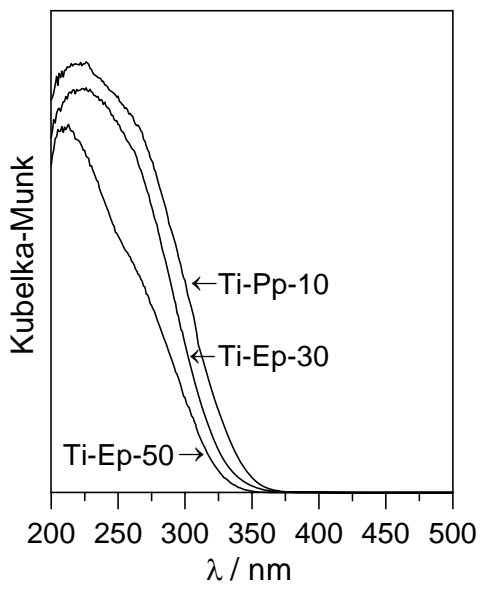

Fig. 5. DRUV-Vis spectra of Ti-MCM-41.

in a tetrahedral environment, octahedrally coordinated aluminium species are also present in the samples prepared by this method using aluminium isopropoxide. With regard to Ti-MCM, the diffuse reflectance UV-Vis spectra shown in Fig. 5, indicate that the materials contain mainly isolated $\mathrm{Ti}$ (IV) incorporated in the silicate structure, as the maxima at $212 \mathrm{~nm}$ (Ti-Ep-50) and at 225nm (Ti-Ep-30 and Ti-Pp-10)) can be ascribed to tetracoordinated species, namely tetrapodal $\left(\mathrm{Ti}(\mathrm{OSi})_{4}\right)$ and tripodal (such as $\left.\mathrm{Ti}(\mathrm{OH})(\mathrm{OSi})_{3}\right)$ units [12]. For the higher $\mathrm{Ti}$ content samples (Ti-Ep-30 and Ti-Pp-10) it is evident that there is broadening of the band to higher wavelength. This indicates an increase of penta- and hexacoordinated species, probably due to the formation of partially polymerised species with Ti-O-Ti bonds or nanodomains of amorphous $\mathrm{TiO}_{2}-\mathrm{SiO}_{2}$, which also exist at lower titanium content but to a much lesser extent. Taking these results into account and that the introduction of $\mathrm{Ti}$ with $\mathrm{Si} / \mathrm{Ti}=50$ hardly changed the pore volumes and regularity, it is reasonable to consider that the extraframework species contribute to the disruption of structural properties with increasing titanium content.

\subsection{Structural stability towards water vapour}

It can be seen from Fig. 6 that the water vapour isotherms obtained in the alumino and titanosilicate samples present some similar features indicating an initial surface with low adsorption affinity which undergoes hydroxylation during the determination of the first isotherm. In both cases the pore filling step of the second isotherm occurs at lower relative pressures, the hysteresis loop is narrower and the desorption of the first and second isotherms practically coincide. Additionally, the values of volume adsorbed at $\mathrm{p} / \mathrm{p}^{0}=0.9$ presented in Table 2 for the two $\mathrm{Al}$ and Ti containing samples are very similar which is consistent with the results obtained from nitrogen adsorption. Also, the higher uniformity of pore size of Ti-Pp-30 previously inferred from Fig.1 results in a pore filling step, in the water isotherm, steeper than in the case of Al-Pp-30. For this sample the pore filling occurs at lower relative pressure ( 0.56 ) than for Ti-Ep-30 ( 0.59) which may result from differences in surface chemistry, as expected on the basis of the presence of the different metals incorporated in the silicate structure. In fact, an estimate of the Kelvin radius $\left(\mathrm{r}_{\mathrm{K}}\right)$, gives 1.8 and $2.0 \mathrm{~nm}$, respectively, for $\mathrm{Al}-\mathrm{Pp}-30$ and $\mathrm{Ti}-\mathrm{Ep}-30$, indicating that at the onset of condensation the preadsorbed layer of water is different in the two samples, as the pore size was similar taking into consideration the nitrogen adsorption results.

The general shape of the water isotherms is quite similar to those previously obtained for pure silica samples [5]. However, there is an important difference: after the step the second isotherm is coincident (Al-Pp-30) or only slightly lower (Ti-Pp-30) than the first, which is in marked contrast with the behaviour of pure silica MCM-41 for which the limiting uptakes on repeat runs were significantely reduced. The comparison of the results of characterization by $\mathrm{XRD}$, nitrogen and hydrocarbon adsorption, before and after exposure to water vapour shown in Figs. 7-8 and Table 2, clearly indicates that the materials still retain considerable structural ordering and high pore volumes and that structural alterations occurred mainly during the first isotherm and to a much lesser extent than with pure silica materials [5]. This is also in 

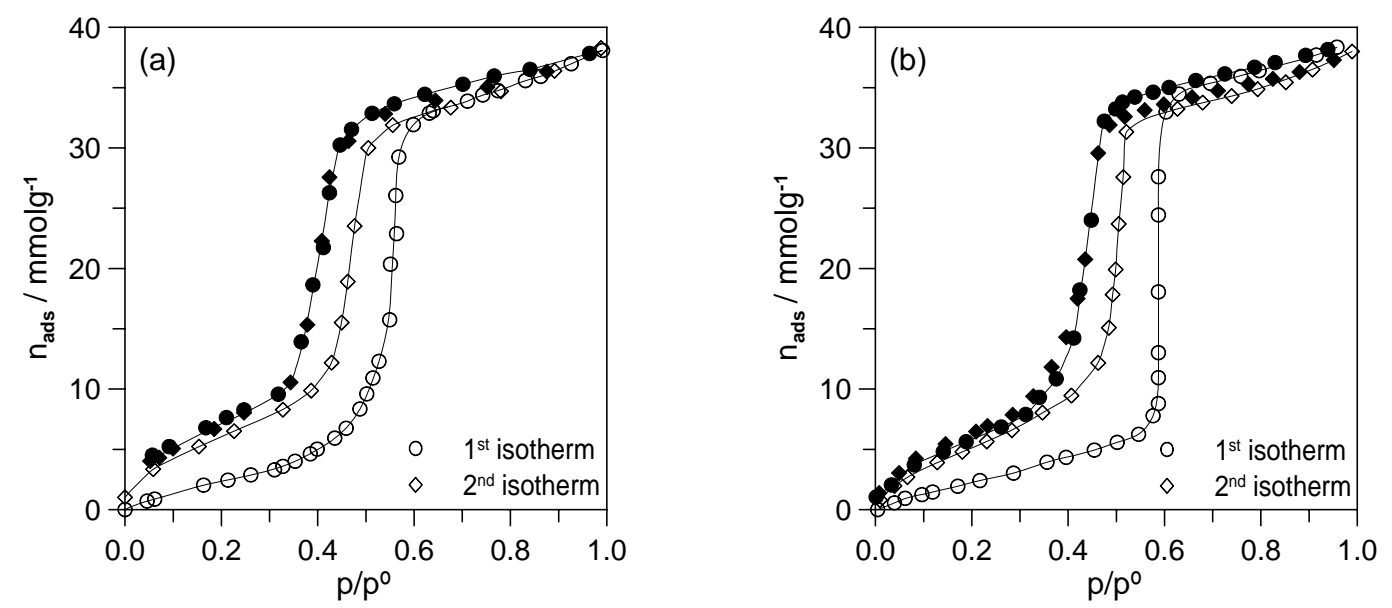

Fig. 6. Water vapour adsorption-desorption isotherms determined at 298K on: (a) Al-Pp-30 and (b) Ti-Ep-30. (empty symbols: adsorption, filled symbols: desorption)

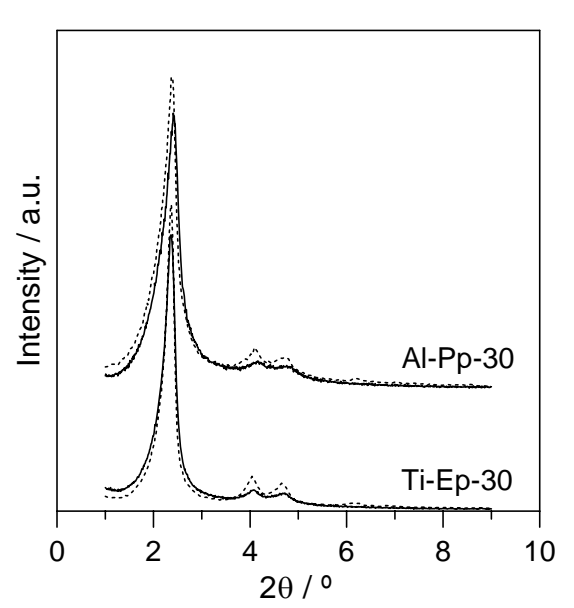

Fig. 7. X-ray powder diffraction patterns of Al-Pp-30 and Ti-Ep-30 before (---) and after water vapour adsorption (-).

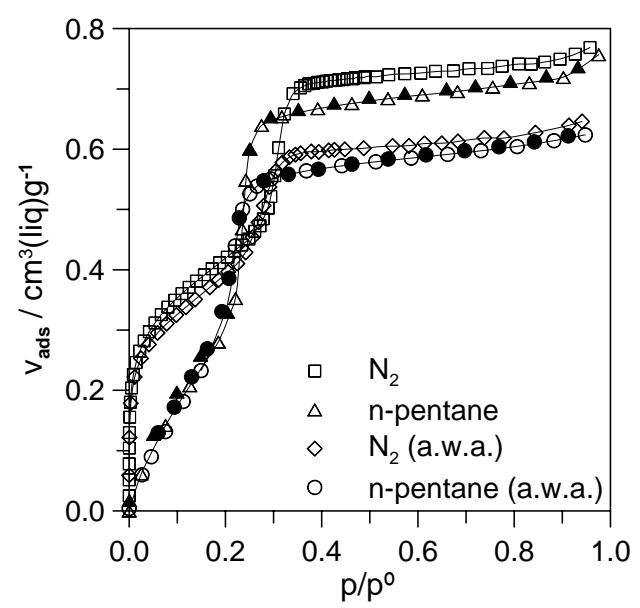

Fig. 8. Nitrogen, at 77K, and n-pentane, at 298K, adsorption isotherms determined on Ti-Ep-30 before and after water vapour adsorption (a.w.a.). (empty symbols: adsorption, filled symbols: desorption).

Table 2

Results of the analysis of water vapour isotherms at $298 \mathrm{~K}$ and of the characterisation of samples before and after water vapour adsorption (a.w.a.) by XRD, nitrogen adsorption at $77 \mathrm{~K}$ and hydrocarbon adsorption at $298 \mathrm{~K}$.

\begin{tabular}{|c|c|c|c|c|c|c|c|c|}
\hline \multirow{2}{*}{ Sample } & $X R D$ & \multicolumn{2}{|c|}{ Water adsorption } & $\begin{array}{c}\mathrm{C}_{\mathrm{n}}{ }^{*} \\
\text { adsorption }\end{array}$ & \multicolumn{4}{|c|}{ Nitrogen adsorption } \\
\hline & $\begin{array}{c}a_{0} \\
(\mathrm{~nm})\end{array}$ & $\begin{array}{r}\mathrm{V}_{0.9}(1) \\
\text { (cm }\end{array}$ & $\begin{array}{l}\mathrm{V}_{0.9}(2) \\
\left.g^{-1}\right)\end{array}$ & $\begin{array}{c}\mathrm{V}_{0.9} \\
\left(\mathrm{~cm}^{3}(\mathrm{liq}) \mathrm{g}^{-1}\right)\end{array}$ & $\begin{array}{c}\mathrm{A}_{\mathrm{s}} \\
\left(\mathrm{m}^{2} \mathrm{~g}^{-1}\right)\end{array}$ & $\begin{array}{c}\mathrm{A}_{\text {ext }} \\
\left(\mathrm{m}^{2} \mathrm{~g}^{-1}\right)\end{array}$ & $\begin{array}{c}\mathrm{V}_{\mathrm{p}} \\
\left(\mathrm{cm}^{3}(\mathrm{liq}) \mathrm{g}^{-1}\right)\end{array}$ & $\begin{array}{c}\mathrm{d}_{\mathrm{p}}(\mathrm{H}) \\
(\mathrm{nm})\end{array}$ \\
\hline \multirow{2}{*}{$\begin{array}{c}\text { Al-Pp-30 } \\
\text { a.w.a. }\end{array}$} & 4.32 & \multirow{2}{*}{0.66} & \multirow{2}{*}{0.66} & 0.71 & 976 & 71 & 0.70 & 3.01 \\
\hline & 4.26 & & & 0.64 & 910 & 37 & 0.60 & 2.79 \\
\hline \multirow{2}{*}{$\begin{array}{c}\text { Ti-Ep-30 } \\
\text { a.w.a. }\end{array}$} & 4.36 & \multirow{2}{*}{0.68} & \multirow{2}{*}{0.66} & 0.72 & 956 & 28 & 0.72 & 3.11 \\
\hline & 4.34 & & & 0.62 & 886 & 49 & 0.59 & 2.82 \\
\hline
\end{tabular}

* n-hexane for Al-Pp-30 and n-pentane for Ti-Ep-30. 
marked contrast with some hydrothermally synthesised Al-MCM-41 and Ti-MCM-41 whose stability was extremely low [6,7]. Furthermore, Al-Pp-30 appears to be slightly more resistent than Ti-Ep-30. It should also be noted that the reduction of pore volume results partially from the increase in mass due to the residual water present after the determination of the isotherms as well as from the pore narrowing that occurred. Taking into account that during the measurements the samples were in contact with pure water vapour for over a month, it is evident that these samples are reasonably stable. So, this study shows that the introduction of the titanium and of aluminium lead to an increase in the structural stability, which may be due to the formation of stronger Si-O-M bonds and a higher degree of condensation in the pore walls. The presence of extraframework species may also contribute to the enhancement of stability, by avoiding the interaction of water with nearby Si-O-Si bonds.

\section{CONCLUSIONS}

The results show that the room temperature synthesis method previously developed for MCM-41 containing aluminium is an adequate method for obtaining titanosilicate of different Si/Ti with highly regular MCM-41 structure, high pore volume, very uniform pore size and containing tetracoordinated titanium. Additionally, it was found that the incorporation of titanium has a less disruptive effect on the pore structure than aluminium. The increase of Ti or Al content leads to a gradual reduction of the quality of the pore structure, but no significant differences were observed with the different metal sources used.

The introduction of either titanium or aluminium by this method leads to materials that are considerably more stable towards prolonged exposure to water vapour than pure silica grades of MCM-41 as well as some hydrothermally synthesised Al and Ti-MCM-41 samples.

\section{Acknowledgements}

The authors are grateful to the Fundação para a Ciência e a Tecnologia (FCT, Portugal) and the Fundo Europeu para o Desenvolvimento Regional (FEDER) for financial support (project no. POCTI/CTM/45859/2002).

\section{REFERENCES}

[1] A. Taguchi and F. Schüth, Micropor. Mesopor. Mater., 77 (2005) 1.

[2] A. Matsumoto, H. Chen, K. Tutsumi, M. Grun and K. Unger, Micropor. Mesopor. Mater., 32 (1999) 55.

[3] T.N. Silva, J.M. Lopes, F.R. Ribeiro, M. Ribeiro Carrott, P.C. Galacho, M.J. Sousa and P. Carrott, React. Kinet. Catal. Lett., 77 (2002) 83.

[4] A. Tuel, Micropor. Mesopor. Mater., 27 (1999) 151.

[5] M.M.L. Ribeiro Carrott, A.J.E. Candeias, P.J.M. Carrott, and K.K. Unger, Langmuir, 15 (1999) 8895.

[6] X.S. Zhao, F. Audsley and G.Q. Lu, J. Phys. Chem. B, 102 (1998) 4143.

[7] K.A. Koyano and T. Tatsumi, Micropor. Mater., 10 (1997) 259.

[8] M. Grün, K. Unger, A. Matsumoto and K. Tsutsumi in Characterisation of Porous Solids IV, B. McEnaney, T.J. Mays, J. Rouquerol, F. Rodriguez-Reinoso, K.S.W. Sing and K.K. Unger (eds.), Royal Society of Chemistry, Cambridge, 1997, p.81.

[9] M. Kruk, M. Jaroniec and A. Sayari, J. Phys. Chem. B, 101 (1997) 583.

[10] M.M.L. Ribeiro Carrott, A.J. Candeias, P.J.M. Carrott, P.I. Ravikovitch, A.V. Neimark and A.D. Sequeira, Micropor. Mesopor. Mater., 47 (2001) 323.

[11] P. Ågren, M. Linden, J.B. Rosenholm, R. Schwarzenbacher, M. Kriechbaum, H. Amenitsch, P. Laggner, J. Blanchard and F. Schüth, J. Phys. Chem. B, 103 (1999) 5943.

[12] P. Ratnasamy, D. Srinivas and H. Knözinger, Adv. Catal., 48 (2004) 1. 